\title{
sciendo
}

\section{Identifying Carbon Reduction Potentials in Road Transportation: Creating a Carbon-Tracking Tool for Small and Medium Enterprises (SMEs)}

\author{
Wolfram GROSCHOPF ${ }^{1}$, Elmar FUERST ${ }^{2}$, Sebastian KUMMER ${ }^{3}$, David HEROLD ${ }^{4 *}$ \\ ${ }^{1,2}$ WU / Vienna University of Economics and Business, Institute for Transport and Logistics Management, \\ Welthandelsplatz 1, Vienna, 1020, Austria \\ ${ }^{3}$ Jilin University, School of Management, Qianjin Street 2699, Changchun, China \\ ${ }^{4}$ Griffith University, Department of Business and Asian Studies, Parkland Drive, Southport, \\ Gold Coast, QLD 4222, Australia
}

\begin{abstract}
Improving environmental performance of road transport through carbon reduction initiatives can be a demand challenge, in particular for Small and Medium Enterprises (SMEs). Whether existing carbon reduction potentials are effectively and efficiently uncovered largely depends on the availability of information as well as on how to make use of it. An often-observed problem is the lack of tools for SMEs to obtain useful carbon-related information from road transport. Against the background of a case study of the carbon-tracking tool $\mathrm{CO}_{2}$-Tec, this paper highlights the importance of decision-making information and demonstrates how carbon reduction potentials in road transportation can be uncovered for SMEs. Particular attention is paid to the information needs of the SMEs and how these needs can be fulfilled. The analysis of the results suggests a pattern of action that increases the efficacy and efficiency of information management and use in corporate practice.
\end{abstract}

Keywords - Carbon reduction; $\mathrm{CO}_{2}$; carbon tracking tool; sustainability; logistics; road transportation; SMEs

\section{INTRODUCTION}

A core aim of corporate management is to enhance the economic efficiency within a company. Environmental management, on the other hand, has the objective to enhance environmental performance which should at the same time - in an ideal case - also contribute to the aim of economic improvement [1]-[3]. Existing research indicates that significant efficiency improvement potentials exist with regard to both, environmental and economic performance, particularly in the logistics industry [4]-[6]. In this context, carbon reduction initiatives have shown to be a valuable approach to improving economic performance by considering the impacts of the business on the environment and vice versa [7]-[9].

Although various approaches to reduce carbon emissions exist [8], [10], [11], their applicability depends on available and retrievable information in the company where carbon reduction initiatives are applied. A major challenge is the collection and interpretation of available carbon-related information [12]-[14] and logistics managers responsible for carbon reduction often seem to be hindered by the lack of tools which provide relevant information and support

\footnotetext{
* Corresponding author.

E-mail address: d.herold@griffith.edu.au

(c)2019 Wolfram Groschopf, Elmar Fuerst, Sebastian Kummer, David Herold.

This is an open access article licensed under the Creative Commons Attribution License (http://creativecommons.org/ 
decision making [15], leading to calls to use advances in technology and develop relevant carbon tracking tools to help "companies reconcile efficiency and resilience goals" [16].

Although information availability can be considered as a generic problem, in-depth research on environmental information systems needs of decision makers has developed only recently, in particular for a Small and Medium Enterprise (SME) environment [17], [18]. To better understand the carbon-related information needs for road transport in an SME context, this paper uses a case study of the carbon-tracking tool $\mathrm{CO}_{2}$-Tec to identify what information can serve the needs of managers to reduce carbon emissions and how relevant information can be provided. In particular, this case study looks into the decision situations which arise when applying carbon accounting for logistics decision makers and identifies a suitable tool for providing the required decision-making information. The example of road transport in an SME context is particularly interesting as various authors have highlighted the carbon reduction potential for economic and environmental improvement [19], [20].

Section 2 provides an overview of the environmental developments in logistics industry in a SME context and highlights the relevance of analysing carbon reduction potentials. Section 3 presents the methodology and the research approach that lead to the analysis of the carbon-tracking tool. The core of this paper is section 4, which demonstrates how the carbon-tracking tool was used to support the process of identifying carbon reduction potentials and what can be learned from the case. Section 5 concludes with the main implications and observations in applying the carbon-tracking tool to support carbon emissions reduction.

\section{The Role of CARbon EMISSIONS In ROAD Transportation IN THE CONTEXT OF SMES}

The transport sector accounts for about 10 per cent of the total carbon emissions worldwide, with almost three-quarters coming from road freight transport [21]. In contrast to the other sectors, emissions of the road transport industry have risen by nearly $30 \%$ since the reference year 1990 [22]. To address this problem, mechanisms were developed and implemented globally as an effort to decrease carbon emissions with suitable means in most sectors. For example, the European Union (EU) implemented the European Union Emissions Trading System (EU ETS) in 2012 covering carbon emissions and other greenhouse gases from energy intensive industries [23]. With regard to the transport industry, EU ETS currently only covers emissions from air transport. While the European Standard EN 16258 provides a standardized but complex calculation method for transport emissions mainly adopted by large logistics companies, the transport sector lacks carbon reduction initiatives, or any mechanism to compensate for external effects in the road transportation. The need for measurement and reduction of transport related carbon emissions is obvious, the lack of available information and communications technology (ICT) tools leads to uncertainty among shippers and transport companies [15], [24].

From an academic view, despite the large body of literature on 'green logistics' [25]-[27] and 'green supply chain management' [28]-[30], investigations and discussions about practical examples to reduce carbon emissions in road freight transportation and transport management are limited. Literature in this context mainly addresses policy or planning issues [31]-[33] rather than environmental management information systems on a corporate level. However, due to the increasing discussion how transport and logistics companies view environmental management, the question remains which practices and tools are applied to enhance corporate environmental performance [34]-[36].

In particular, SMEs, embedded in highly competitive environments such as transport industry, conducting local business hardly focus on their environmental performance at all [2], [37] and significantly lack sustainability and carbon reporting. The main barriers for corporate action in 
this field are the complexity of emissions calculation and the investment in environmental management systems resulting in additional costs for software development or acquisition, staff training and integration in the order fulfilment and reporting process [15]. Moreover, often managers of small firms consider their own moral standards to draw decisions [38], but regard environmental policies as an additional burden and as a cost-factor as well, particularly when regulations are imposed by the government. Other internal barriers are lack of resources, poor understanding and perception, problems connected with the implementation, low attitudes and aversive company culture [39]. Most important external barriers to environmental management implementation in SMEs are problems related to certifiers/verifiers, market uncertainties, institutional weaknesses and lack of support and guidance [40]. Furthermore, many (particularly not family-run) small and medium-sized enterprises are stuck in rather short-term oriented planning and goals and therefore are less proactive in environmental management.

Environmental concerns and positive attitudes towards environmental management exist, but only few small or medium-sized businesses are able to transfer this into proactive environmental behaviour [41]. Although existing research shows that SMEs can benefit from (formal and informal) environmental management, the implementation of environmental management or information systems in small and medium-sized trucking companies is the result of economic management choices, irrespective of their (good or bad) environmental impact. So far, the development and the implementation of formal environmental systems seems to be driven by large logistics companies, mainly in order to meet forwarders' and regulatory requirements. As such, SMEs lack an affordable solution to track their carbon emissions. This paper uses a case study of the carbon-tracking tool $\mathrm{CO}_{2}-\mathrm{Tec}$ to investigate the information needs, the business requirements and how the tool can help to identify carbon reduction potentials in road transportation from an SME perspective.

\section{RESEARCH APPROACH}

While large logistics companies may have sufficient resources to develop individual solutions to track carbon-related information, small and medium-sized companies - particularly in the trucking industry - face several internal and external barriers to invest in ICT tools or develop an own solution [15]. To address this organizational problem, we investigate the creation process of the IT artifact $\mathrm{CO}_{2}$-Tec, a web-based solution that tracks carbon emissions specifically for road transportation. In addition to the carbon calculation for full truckloads, the tool allows for the allocation of emissions to partial loads, particularly in mixed laden transport units and multi-staged transports. According to Hevner et al. [42], artifacts "are rarely full-grown information systems that are used in practice", but rather innovations that define ideas and products through which the analysis and the use of information can be effectively and efficiently accomplished.

To investigate the information needs process that addresses all requirements for a carbon-tracking tool for road transport, we follow the 'design science research cycles' framework for Information Systems (IS) research projects from [42] (Fig. 1). Design science research is motivated by the desire to improve the environment by the introduction of new artifacts and the processes for building these artifacts, which consists of three inherent research cycles [42]. First, the Relevance Cycle bridges the contextual environment of the research project with the design science activities. In our case, we focus on the environmental impact of road transport where companies, in particular SMEs, face several challenges to use or implement a carbon-tracking tool. Road freight transport is by far the most important transport mode regarding transport volumes and carbon emissions output. The flexibility and speed of road transport as well as the dense road network are unique features that other transport modes are unable to replace. 


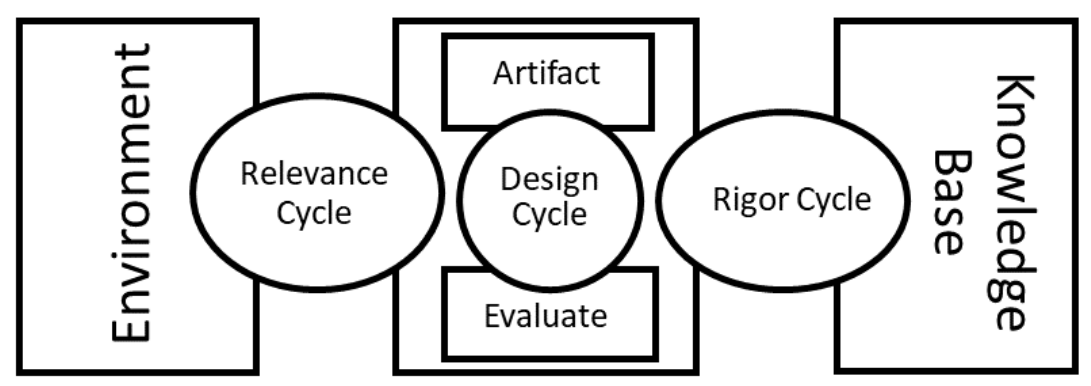

Fig. 1. Design Science Research Cycles [42].

Second, the Rigor Cycle connects the design activities with the knowledge base of scientific foundations, experience and expertise that informs the research project. For our research project, existing methods for the calculation of $\mathrm{CO}_{2}$ emissions such as the GHG Protocol, PAS 2050 or ISO 14064 provide general guidelines and help to set limits for corporate and product-related emissions calculation [43]. Others such as the EN 16258 specify a standard for calculation of transport-related $\mathrm{CO}_{2}$ emissions and other relevant emissions in form of $\mathrm{CO}_{2}$ equivalents. In addition, databases for emission factors (e.g. HBEFA, GEMIS) provide data related to emissions of different air pollutants dependent on several variables such as vehicle or fuel type, different traffic situations and pitch attitudes [44]. These values form the base for emission calculations and carbon calculation tools.

Third, the central Design Cycle iterates between core activities of building and evaluating the design artifact and processes of the research. The goal of the research project was to design an application capable of breaking down the total emissions to different shipments or different logistical units in these calculations, thereby allowing to evaluate alternative forms of transport with respect to carbon reduction and to calculate and present potential and accomplished achievements in the reduction of carbon emissions. As all three cycles are crucial in our design science research project, and as "it is important for audiences to understand the processes by which the artifact was constructed and evaluated" [45], Section 4 will present the steps of the creation process and its associated information needs development according to each step.

\section{Findings: The Creation Process Of The CO2-Tec ToOl}

\subsection{Relevance and Environment (the Relevance Cycle)}

Given the lack of tools as well as internal and external barriers for SMEs to track carbon emissions in road transportation, a development of a carbon-tracking tool that specializes in road transport may present a solution. Decision-making in transport management requires information on environmental effects of mode shifts and reduction of the impact of transport by improved vehicle utilisation [46]. For an extensive presentation of a product- or supply chain-oriented Carbon Footprint, it is necessary to calculate and evaluate transport-induced emissions [47], [48].

As the relevance of a design-science research effort is related to the "constituent community' [42], which consists mainly of the practitioners who manage and operate the tool, the process included a detailed analysis of relevant business cases of companies within the logistics sector in order to realistically portray different types of production in road freight transport. Parameter definitions include only information, which is regularly available in SMEs and helps to calculate the carbon emissions of individual company-specific transport chains. In particular, the 
tool should enable users to model and analyse multi-stage transport chains with respect to current carbon emissions according to the freight transports (e.g. full load shipments, part load shipments, mixed loads, round trips) as well as the subsequent allocation of emissions to those shipments.

The $\mathrm{CO}_{2}$-Tec Emission Calculator enables users to model and analyse multi-stage transport chains with respect to current carbon emissions (full load shipments, part load shipments, mixed loads, round trips) and the subsequent allocation of emissions to those shipments. Moreover, it allows evaluating alternative forms of transport with respect to carbon reduction and to calculate and present potential and accomplished achievements in the reduction of carbon emissions. The tool also allows for the calculation of up to ten different sections per transport. The results can either be presented in total or per section, enabling users to save reference transports for future calculations, administrate emission statements and create emission scenarios by use of different vehicles or routings [17], [18].

The calculation of distances is based on components of a geo-information database. Emission factors are based on the handbook of emission factors in road transport [49] providing specific emission values for different types of vehicles, different types of roads (motorway, rural road and urban area) and for the weight-related load factor. It includes the actual energy consumption of upstream processes, which is factored into the algorithm [50].

\subsection{Rigor and the Knowledge Base (the Rigor Cycle)}

Based on standardised calculation parameters and GIS-data, the model calculates exact door-todoor $\mathrm{CO}_{2}$ emissions of individual transport chains. In order to provide accurate results, it needs to be complemented with company-specific data by users. The emissions produced are mostly dependent on the type of vehicle, which differs by EURO-class and weight. After the analysis of a variety of business cases for full and part load transports, round trips and courier express and parcel services, relevant transport units have been defined for various types of vehicles. These are related to their respective maximum load capacity, leading to a classification of twelve different types. The model includes small delivery trucks with a maximum permissible laden weight of 3.5 tons as well as all types of light and heavy utility vehicles. It also provides an additional differentiation for heavy utility vehicles with maximum permissible laden weight of 40 tons to factor in the different possibilities of loading, as there can be massive disparities concerning the respective maximum load capacity. Therefore, from a logistical point of view, all relevant maximum capacities are available considering load capacity, transport volume, loading meter, number of pallet storage positions and number of positions for containers with fixed wheels.

A calculation of part loads is also possible. In order to calculate the carbon emissions of part loads, it is necessary to distinguish between user-relevant transport units and loading units from a logistical point of view. The term "transport unit" describes a packaging unit (e.g. crate) of the transport goods (e.g. milk). "Loading unit" denominates the loading equipment (e.g. pallet), which carries the transport units. If transport units are used without loading units, i.e. are directly stored in the vehicle, the loading unit has to be "loading meter" or "cubic meter". For an exact emission calculation, it is necessary to enter information about source, drain, hub or depot and the route as well as the exact weight of the shipment. The calculated emissions can thus be perfectly allocated and associated with specific shipments. If, for instance, a single package is transported only, all emissions of the related transport stage are charged to the particular package.

Other variables include the load factor and empty journeys. The load factor of the vehicles is an important parameter for the calculation, as a higher utilisation, respectively a higher tonnage, also causes a higher emission of $\mathrm{CO}_{2}$ (see Fig. 2). However, from a logistical point of view, the load factor is not necessarily related to tonnage only, but can also be related to the volume or the industry-specific amount of transported loading units. 


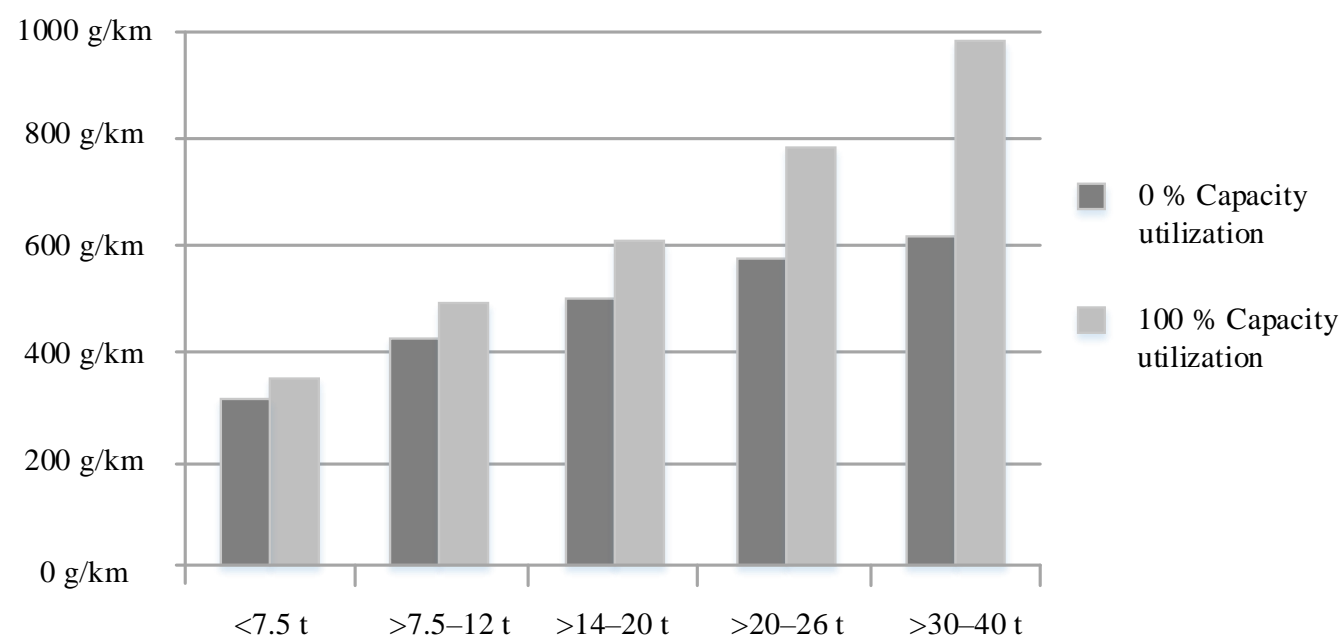

Fig. 2. Emission factors with respect to load factor [49].

The consideration of empty journey through an empty journey quota describes the number of kilometres of a journey which are realised without transporting any cargo - but are still related and necessary to conduct that basic transport. The higher the quota, the higher the emission values for this transport. Thus, the quota is highly influenced by the type of transport observed, so a constant calculation like a fixed rate is not feasible.

TABLE 1. TyPE SIZES, SPACES AND INTER EMPTY TRIPS ASSOCIATED WITH DIFFERENT TYPES OF TRANSPORT EXPRESSED AS QUOTA OF THE BASIC JOURNEY (BASED ON OBSERVATIONS BY THE PROJECT TEAM)

\begin{tabular}{ll}
\hline Transport type & Empty trip quota, \% \\
Matched direct transports & Towards 0 \% \\
Full load long distance transports & $5-20$ \\
Part-load transports & $25-50$ \\
Special transports & $100+$ \\
\hline
\end{tabular}

Our sample research documents this factor and shows the effects of different types of transport on the emission values (Table 1). The table shows that a calculation of the quota with fixed constants (e.g. distance) is not practicable for the model. The empty trip quota is therefore calculated based on a user input. The system assumes that the empty trip takes place on the same composition of roads (motorway, rural road, urban area) with the same (unladen) vehicle as the original transport on the observed section. Thus, both a direct user input with variable parameters and the development of a GIS-independent round trip calculation are implemented.

\subsection{The Artifact and Evaluation (the Design Cycle)}

The design cycle is at the heart of a research science design project, which generates design alternatives and evaluates the alternatives against the requirements from the relevance cycle as well as the methods drawn from the rigor cycle [45]. Through the artifact, $\mathrm{CO}_{2}-\mathrm{Tec}$, we extended the knowledge base by applying existing knowledge in a new and innovative way. 
$\mathrm{CO}_{2}$-Tec enables users to conduct differentiated carbon calculations for partial loads (transport units) and mixed laden loading units based on commonly available information. Practical application of the tool is supported by an easy-to-use graphical user inter-face providing an integrated help function and FAQs while accuracy and transparency of results are secured by use of verified truck emission data and door-to-door routing by verified databases.

The following example demonstrates the functionalities of $\mathrm{CO}_{2}-\mathrm{Tec}$ in two scenarios (Table 2): Scenario 1 illustrates in a homogenous part-load scenario, while Scenario 2 shows a mixed carrier scenario in the second section. Both scenarios have the same amount of transport units regarded in the calculation throughout different transport sections: 200 crates of long-life milk a $25 \mathrm{~kg}$ packed on euro-pallets. In Scenario 1, one pallet carries 20 crates of long-life milk while the truck carries an additional 70 crates (3.5 pallets) of long-life milk for another customer, which are not considered in the calculation. There are no empty drives in Scenario 1. After the goods have been delivered in Mauthausen the truck is loaded with an additional 10 crates of cocoa a $35 \mathrm{~kg}$ and the goods are transported to Salzburg in another medium-sized truck (Scenario 2). The truck returns to the depot empty after delivering the goods, which results in an empty drive quota of $15 \%$.

TABLE 2. OVERVIEW TRANSPORT EXAMPLE

\begin{tabular}{|c|c|c|}
\hline Data & Scenario 1 & Scenario 2 \\
\hline Type of transport & Domestic road transport Austria & Domestic road transport Austria \\
\hline Main road type & Federal Road & Highway \\
\hline Section & $\begin{array}{l}\text { Waidhofen (producer) - } \\
\text { Mauthausen (depot) }\end{array}$ & $\begin{array}{l}\text { Mauthausen (depot) - Salzburg } \\
\text { (customer) }\end{array}$ \\
\hline Distance & $122.79 \mathrm{~km}$ & $147.49 \mathrm{~km}$ \\
\hline Vehicle & $\begin{array}{l}18 \text { t, EURO 5, storing positions for } \\
18 \text { pallets }\end{array}$ & $\begin{array}{l}26 \text { t, EURO 5, storing positions for } \\
20 \text { pallets }\end{array}$ \\
\hline $\begin{array}{l}\text { Average fuel } \\
\text { consumption }\end{array}$ & $25.71 / 100 \mathrm{~km}$ & $28.81 / 100 \mathrm{~km}$ \\
\hline Transport units & 200 crates long-life milk a $25 \mathrm{~kg}$ & 200 crates long-life milk a $25 \mathrm{~kg}$ \\
\hline Loading units & 20 crates per pallet & 20 crates per pallet \\
\hline $\begin{array}{l}\text { Other cargo } \\
\text { (disregarded) }\end{array}$ & 70 crates long-life milk & - \\
\hline $\begin{array}{l}\text { Mixed load } \\
\text { (disregarded) }\end{array}$ & - & $\begin{array}{l}\text { Additional } 10 \text { crates of cocoa a } 35 \mathrm{~kg} \\
\text { per pallet }\end{array}$ \\
\hline $\begin{array}{l}\text { Percentage of empty } \\
\text { journeys }\end{array}$ & $0 \%$ & $15 \%$ \\
\hline
\end{tabular}

Scenario 1 shows the modelling of a homogenous part load transport, where the user has to enter the type of vehicle, the specific loading unit, the weight of the loading unit and how many loading units (crates) are carried per standardised loading equipment (pallet). Additionally, the total capacity utilisation needs to be entered based on the ratio of used capacity to available capacity, which allows for the calculation of the percentage the 200 observed crates produce within the total emissions of the transport. The calculation assumes that the rest of the cargo is also subject to the same volume-weight relation as the 200 crates.

In Scenario 2, the modelling of a mixed loaded carrier can be observed. The cargo is automatically assigned to the next section by the system, but the used vehicle has to be defined for every new section. To calculate a mixed load, the user needs to enter additional information: What percentage of the volume of the loading unit is used by the observed cargo on this loading 
unit? What is the percentage of remaining cargo weight on the observed loading unit? Based on these declarations, the system can determine the load of an average loading unit for this section. This also enables the calculation of the total weight and percentage of certain goods on a loading unit based on its weight (Fig. 3).

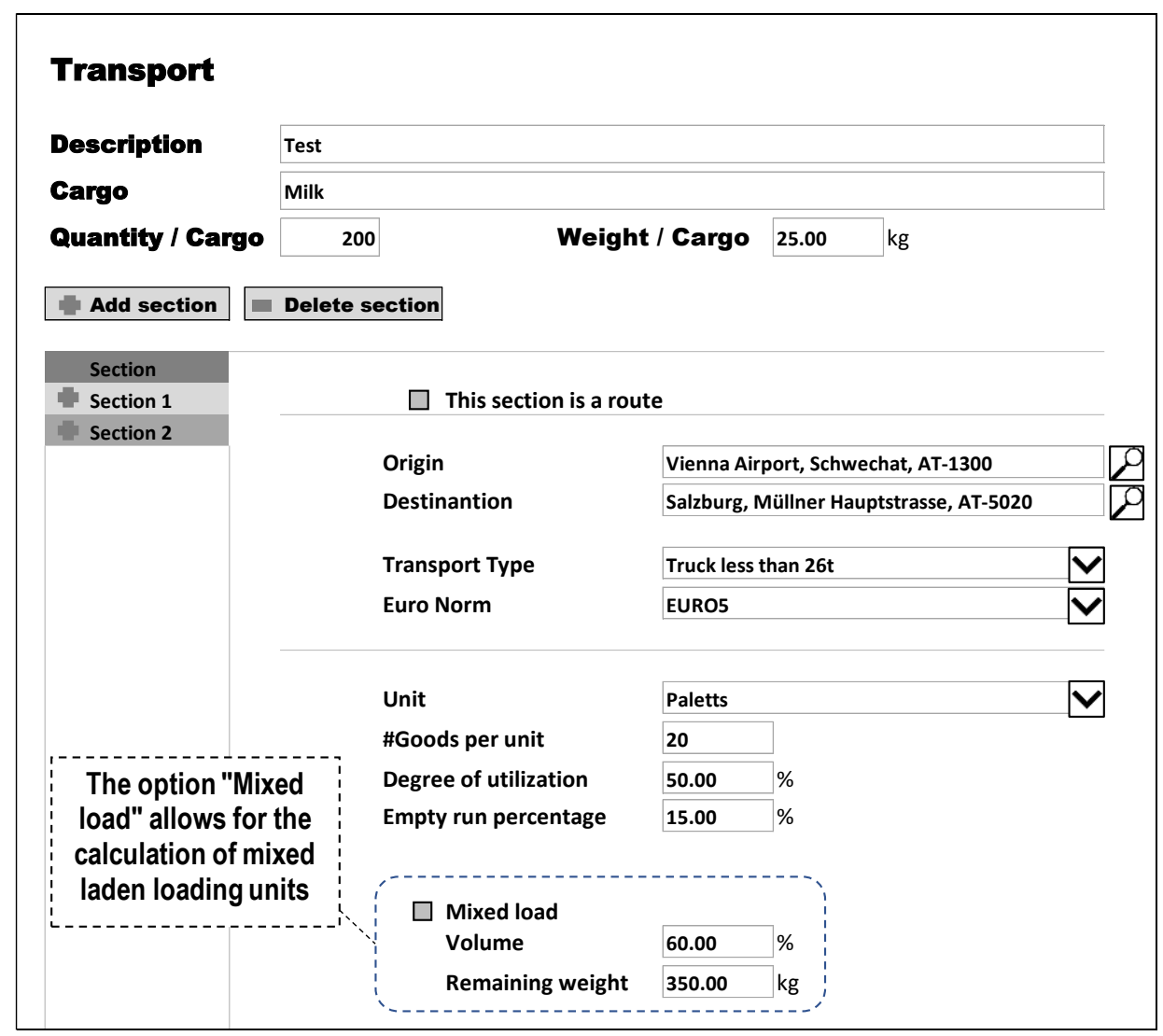

Fig. 3. Input Section 2.

To calculate vehicle-specific emission values, it is necessary to factor in the weight of the additional load as a weight-specific capacity utilisation of a given vehicle. This happens through the interpolation of the emission values according to the handbook of emission factors in road traffic. This yields the weight-specific fraction of emissions of the transported goods.

To calculate the amount of emissions of an average loading unit that can be attributed to the part load of long-life milk, the respective higher quota factor based on the volume-weight-calculation key is used. The total emissions of long-life milk in a mixed load consist of the percentage of the emissions of the observed load from the emissions of an average loading unit and the amount of loading units necessary to transport the shipment. The output is displayed in different ways (Fig. 4). 


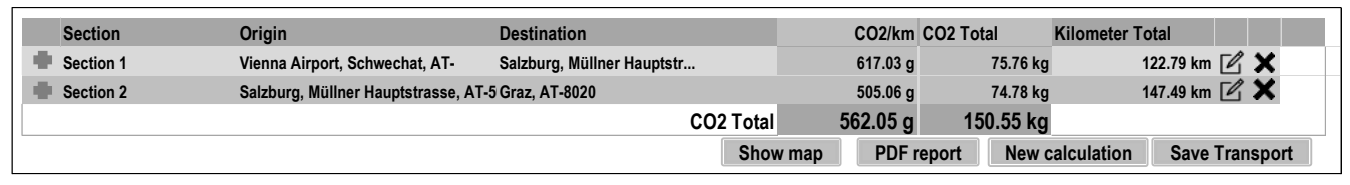

Fig. 4. $\mathrm{CO}_{2}$-emissions per $\mathrm{km}$ and in total.

Eventually, the user has the option to delete or rework single sections, for example when the same amounts of long-life milk are transported with different vehicles or on different sections. Additionally, the user can save the transport for further use and print a report with all parameters and results.

\section{Discussion ANd Conclusions}

The take-home message of this case study on identifying carbon reduction potentials in road transportation for SMEs is three-fold. First, the case study provides an example that increased voluntary environmental initiatives such as carbon-tracking provide an opportunity for SMEs to enhance environmental and economic performance on the basis of relevant and accurate information. A web-designed carbon-tracking tool for SMEs can help to identify and create this kind of information. Second, the case study illustrates that carbon-tracking tools are understood, applicable and suitable to support carbon reduction in road transportation in the context of SMEs. Third and most importantly, only a very limited number of carbon-tracking tools, in particular for road transportation, for SMEs exist, compared to a relatively large number of carbon tracking tools of large logistics companies. This imbalance might trick managers to believe the identifying carbon reduction potentials through effective carbon-tracking tools would be beneficial for large companies only. However, as the case illustrates, actually the opposite is true. An easily accessible web-designed carbon tracking tool for SMEs shows that the identification of carbon reduction potentials is possible by determining the specific transport or shipment mode in multi-stage transport chains based on company-specific data input. In particular, the possibility to choose between detailed and explicit variables for road transport activities (such as load factor, mixed load, part loads, vehicle type) lead to an accurate allocation of emissions for the transport and thus represents a useful tool to identify and reduce carbon emissions.

However, the feedback from logistics companies and providers highlighted also some challenges. On a conceptual level, the model is challenged by the continuous calculation of emissions of intermodal transport chains for the processing of global transports, as this would demand a correct conversion of emissions, especially for rail-, air- and sea transports. The additional diversification of loading units is particularly challenging. This can be shown by the example of air transport, where completely unique container types are used, weight restrictions are very rigorous, and a vast variety of different forms of transport exist. The bulk of transatlantic transports are, for example, not conducted with cargo planes, but as belly cargo in passenger planes.

Additionally, there are opportunities on the conceptual level concerning the development of algorithms to calculate the $\mathrm{CO}_{2}$ emissions of handling and storage processes for standardised loading units. The long-term object consists of a tool for logistics-related carbon footprints for products. This conceptual framework covers the calculation of product-specific $\mathrm{CO}_{2}$ emissions from global, multimodal transport chains based on Extended Car Floating Data (XFCD) including handling and storage processes along the supply chain. In order to realise product lifecycle carbon footprinting, the combination with relevant emissions data from raw material extraction, production, use and recycling is essential. 
Development opportunities from a technical point of view are performance improvements and the definition of an interface for mass data processing, to be able to execute a high number of transports automatically and efficiently in the system. A high number of processed transports can help to create company- and industry-specific benchmarks for the standardised calculation of carbon emissions in the logistics sector. Moreover, so far, the tool is not able to incorporate different fuel types, i.e. a switch to liquefied natural gas (LNG). Not only provides this an opportunity for further research, but also to complement the existing tool and prepare it for future calculations.

As the case study shows, by using carbon-tracking tools, logistics SMEs managers are able to identify their information needs from an environmental information system in a systematic manner. More importantly, the tool not only serves to use information for decision-making situations, but also supports the systemic identification and retrieval of such information. This case study approach can be seen as a guiding example for introducing carbon-tracking on the basis to pursue carbon reduction potentials. Once the decision has been made to identify carbon reduction potentials and valuable information has been retrieved, management may be motivated to establish the carbon-tracking tool on a regular basis

\section{ACKNOWLEDGEMENT}

This research was in part financed by the Austrian Research Promotion Agency FFG within the programme "protecnet in COIN". The following companies participated in this cooperative research project: OeKB Business Services GmbH, ZTL Logistik Schulungs- und Beratungs GmbH, ECONSULT Betriebsberatungsges.m.b.H.

\section{REFERENCES}

[1] Herold D. M., Lee K.-H. Carbon management in the logistics and transportation sector: An overview and new research directions. Carbon Management 2017:8(1):79-97. doi:10.1002/csr.1366

[2] Fürst E., Oberhofer P. Greening road freight transport: Evidence from an empirical project in Austria. Journal of Cleaner Production 2012:33:67-73. doi:10.1016/j.jclepro.2012.05.027

[3] Dieplinger M., Oberhofer P., Fuerst E. W. Why is the transport and logistics sector lacking environmental performance? Lessons from the sectors of production of building materials and wholesaling. In: Dethloff J., Haasis HD., Kopfer H., Kotzab H., Schönberger J. (eds) Logistics Management. Lecture Notes in Logistics. Springer, Cham. 2015. doi:10.1007/978-3-319-13177-1_1

[4] McKinnon A., Piecyk M. Setting targets for reducing carbon emissions from logistics: Current practice and guiding principles. Carbon Management 2012:3(6):629-639. doi:10.4155/cmt.12.62

[5] McKinnon A. C. Product-level carbon auditing of supply chains: Environmental imperative or wasteful distraction? International Journal of Physical Distribution \& Logistics Management 2010:40(1/2):42-60. doi:10.1108/09600031011018037

[6] Herold D. M., Lee K.-H. The influence of the sustainability logic on carbon disclosure in the global logistics industry: The case of DHL, FDX and UPS. Sustainability 2017:9(4):601. doi:10.3390/su9040601

[7] Herold D. M. Has carbon disclosure become more transparent in the global logistics industry? An investigation of corporate carbon disclosure strategies between 2010 and 2015. Logistics 2018:2(3):13. doi:10.3390/logistics2030013

[8] Oberhofer P., Fürst E. Sustainable development in the transport sector: Influencing environmental behaviour and performance. Business Strategy and the Environment 2013:22(6):374-389. doi:10.1002/bse.1750

[9] Fürst E., Oberhofer P., Stöglehner G. Enhancing environmental management in the field of road freight transport. Studies of Organisational Management \& Sustainability 2013:1(2):98-122.

[10] Herold D. M., Lee K.-H. Carbon disclosure strategies in the global logistics industry: Similarities and differences in carbon measurement and reporting. Pathways to a sustainable economy. Springer: 2018. doi:10.1007/978-3-319-67702-6_6

[11] Dobrovnik M., Herold D., Fürst E., Kummer S. Blockchain for and in Logistics: What to Adopt and Where to Start. Logistics 2018:2(3):18. doi:10.3390/logistics2030018

[12] Herold D. M. The influence of institutional and stakeholder pressures on carbon disclosure strategies: An investigation in the global logistics industry. Queensland: Griffith University, 2018.

[13] Schaltegger S., Viere T., Zvezdov D. Tapping environmental accounting potentials of beer brewing: Information needs for successful cleaner production. Journal of Cleaner Production 2012:29-30:1-10. doi:10.1016/j.jclepro.2012.02.011 
[14] Vejvar M., Lai K.-H., Lo C. K., Fürst E. W. Strategic responses to institutional forces pressuring sustainability practice adoption: Case-based evidence from inland port operations. Transportation Research Part D: Transport and Environment 2018:61(B):274-288. doi.org/10.1016/j.trd.2017.08.014

[15] Evangelista P., McKinnon A., Sweeney E. Technology adoption in small and medium-sized logistics providers. Industrial Management \& Data Systems 2013:113(7):967-989. doi:10.1108/IMDS-10-2012-0374

[16] McKinnon A. Rethinking logistics in the light of climate change: Interview with KLU professor Alan Mckinnon. Hamburg: Kuehne Logistics University, 2018.

[17] Groschopf W., Fürst E., Kummer S. $\mathrm{CO}_{2}$-tec transport emission calculator. Berlin: GITO Verlag, 2012.

[18] Groschopf W., Fürst E., Kummer S. In Calculation of CO2 emissions for partial loads and mixed laden transport units in multilevel transport chains with www.CO2-tec.com. European Transport Conference, Glasgow, 2012.

[19] Oberhofer P., Dieplinger M. Sustainability in the transport and logistics sector: Lacking environmental measures. Business Strategy and the Environment 2014:23(4):236-253. doi:10.1002/bse.1769

[20] Piecyk M. I., Björklund M. Logistics service providers and corporate social responsibility sustainability reporting in the logistics industry. International Journal of Physical Distribution and Logistics Management 2015:45(5):459-485 doi:10.1108/IJPDLM-08-2013-0228

[21] McKinnon A. Decarbonizing logistics: Distributing goods in a low carbon world. London: Kogan Page Publishers, 2018.

[22] European Commission. Building the single market for green products - facilitating better information on the environmental performance of products and organisations, 2013.

[23] Brink C., Vollebergh H. R., van der Werf E. Carbon pricing in the EU: Evaluation of different EU ETS reform options. Energy Policy 2016:97:603-617. doi:10.1016/j.enpol.2016.07.023

[24] Piecyk M. I., McKinnon A. C. Forecasting the carbon footprint of road freight transport in 2020. International Journal of Production Economics 2010:128(1):31-42. doi:1016/j.ijpe.2009.08.027

[25] Akyelken N. Green logistics: Improving the environmental sustainability of logistics. Transport Reviews 2011:31(4):547-548. doi:10.1080/01441647.2010.537101

[26] Dekker R., Bloemhof J., Mallidis I. Operations research for green logistics - an overview of aspects, issues, contributions and challenges. European Journal of Operational Research 2012:219(3):671-679. doi:10.1016/j.ejor.2011.11.010

[27] McKinnon A., Browne M., Whiteing A., Piecyk M. Green logistics: Improving the environmental sustainability of logistics. London: Kogan Page Publishers, 2015.

[28] Maditati D. R., Munim Z. H., Schramm H. J., Kummer S. A review of green supply chain management: From bibliometric analysis to a conceptual framework and future research directions. Resources, Conservation and Recycling 2018:139:150-16. doi:10.1016/j.resconrec.2018.08.004

[29] Sarkis J. A strategic decision framework for green supply chain management. Journal of Cleaner Production 2003:11(4):397-409. doi:10.1016/S0959-6526(02)00062-8

[30] Srivastava S. K. Green supply-chain management: A state-of-the-art literature review. International Journal of Management Reviews 2007:9(1):53-80. doi:10.1111/j.1468-2370.2007.00202.x

[31] May A. D., Jopson A. F., Matthews B. Research challenges in urban transport policy. Transport Policy 2003:10:157-164. doi:10.1016/S0967-070X(03)00039-8

[32] Himanen V., Nijkamp P., Padjen J. Environmental quality and transport policy in Europe. Transportation Research Part A: Policy and Practice 1992:26(2):147-157. doi.org/10.1016/0965-8564(92)90009-V

[33] Lee K.-H., Herold D. M. Cultural relevance in corporate sustainability management: A comparison between Korea and Japan. Asian Journal of Sustainability and Social Responsibility 2016:1-21. doi:10.1186/s41180-016-0003-2

[34] Green K., Morton B., New S. Green purchasing and supply policies: do they improve companies' environmental performance? Supply Chain Management 1998:3(2):89-95. doi:10.1108/13598549810215405

[35] Nijkamp P. Roads toward environmentally sustainable transport. Transportation Research A: Policy and Practice 1994:28(4):261-271. doi:10.1016/0965-8564(94)90002-7

[36] Thornton D., Kagan R. A., Gunningham N. Compliance costs, regulation, and environmental performance: Controlling truck emissions in the us. Regulation \& Governance 2008:2:275-292. doi:10.1111/j.1748-5991.2008.00043.x

[37] Lee K.-H., Herold D. M., Yu A.-L. Small and medium enterprises and corporate social responsibility practice: A Swedish perspective. Corporate Social Responsibility and Environmental Management 2016:23(2):88-99. doi:10.1002/csr.1366

[38] Winn M., Pinkse J., Illge L. Case studies on trade-offs in corporate sustainability. Corporate Social Responsibility and Environmental Management 2012:19:63-68. doi:10.1002/csr.293

[39] McKeiver C., Gadenne D. L. Environmental management systems in small and medium businesses. International Small Business Journal 2005:23(5):513-537. doi:10.1177/0266242605055910

[40] Hillary R. Environmental management systems and the smaller enterprise. Journal of Cleaner Production 2004:12:561-569. doi:10.1016/j.jclepro.2003.08.006

[41] Gadenne D. L., Kennedy J., McKeiver C. An empirical study of environmental awareness and practices in SMEs. Journal of Business Ethics 2009:84(1):45-63. doi:10.1007/s10551-008-9672-9 
[42] Hevner A., March S. T., Park J., Ram S. Design science research in information system. MIS Quarterly 2004:28(1):75-105. doi.org/10.2307/25148625

[43] Toffel M. W., Van Sice S. Carbon footprints: Methods and calculations. Boston, 2011.

[44] Zadek H., Schulz R. Methods for the calculation of $\mathrm{CO}_{2}$ emissions in logistics activities, advanced manufacturing and sustainable logistics. Presented at the 8th International Heinz Nixdorf Symposium (IHNS), Paderborn, Germany, 2010. https://doi.org/10.1007/978-3-642-12494-5_24

[45] Hevner A., Chatterjee S. Design science research in information systems. Design research in information systems. Springer: 2010. doi:10.1007/978-1-4419-5653-8_2

[46] Aronsson H., Huge Brodin M. The environmental impact of changing logistics structures. The International Journal of Logistics Management 2006:17(3):394-415. doi:10.1108/09574090610717545

[47] Herold D. M., Lee K.-H. The influence of internal and external pressures on carbon management practices and disclosure strategies. Australasian Journal of Environmental Management 2019:26:63-81. doi:10.1080/14486563.2018.1522604.

[48] Piecyk M. Carbon auditing of companies, supply chains and products. London: Kogan Page, 2010.

[49] INFRAS. Handbuch Emissionsfaktoren des Straßenverkehrs (hbefa 2.1). 2004

[50] Umweltbundesamt. Globales Emissions-Modell integrierter Systeme (gemis). Available: http://www.umweltbundesamt.at/ueberuns/produkte/gemis/
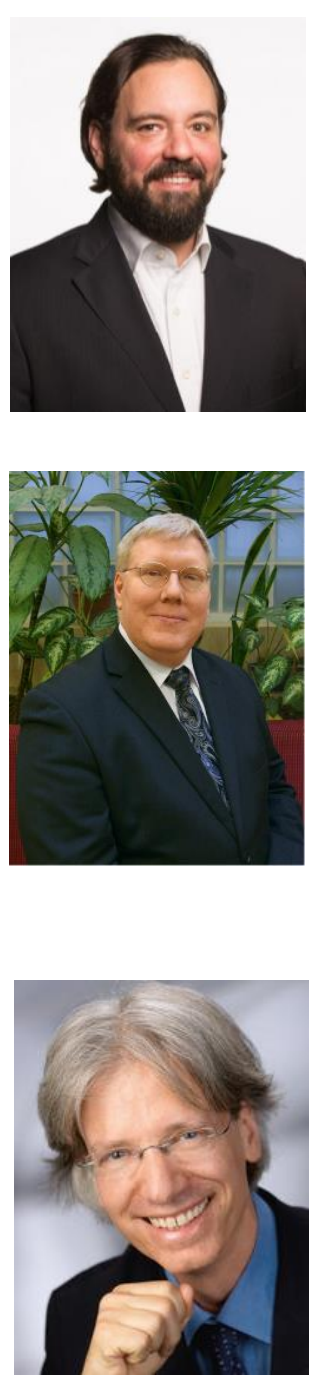

Dr. Wolfram Groschopf received the doctorate degree from the Vienna University of Economics and Business. His research focuses mainly on ecological and social sustainability in transport, logistics and supply chain management, smart city logistics and e-commerce. $\mathrm{He}$ is currently holding a Research Associate Post Doc position at the Institute for Transport and Logistics Management, Vienna University of Economics and Business. Previously he worked as senior lecturer at Vienna University of Economics and Business, management consultant in Austria and as project manager in Belgium.

Assoc. Prof. Mag. Dr. Elmar Wilhelm M. Furst received the doctorate degree from the Vienna University of Economics and Business. His research focuses in sustainability aspects in transportation and logistics as well as on mobility issues for industries, NGOs and society. He is currently Associate Professor at the Institute for Transport and Logistics Management, Vienna University of Economics and Business. Previously he worked as a project head and senior analyst for Statistik Austria.

ORCID ID: https://orcid.org/0000-0001-6939-7307

Professor Dr. Sebastian Kummer is Full Professor and Head of Institute for Transport and Logistics Management at Vienna University of Economics and Business in Austria as well as Endowed Chair at the School of Management at Jilin University in Changchun, China. As a practice-oriented scientist, Prof. Kummer and his team conduct scientific research and corporate projects in the fields of logistics, controlling, supply chain management and sustainability. He developed the Austrian Masterplan for logistics and is member of scientific and industry boards e.g. the Logistics Hall of Fame which honours leading figures in the field of logistics and supply chain management.

ORCID ID: https://orcid.org/0000-0003-1007-4428 


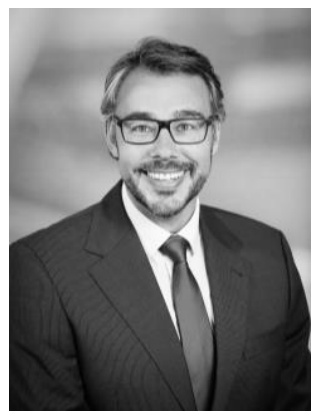

Dr. David M. Herold received the doctorate degree from Griffith University, Australia. His research deals with the topic of sustainable logistics with an environmental focus as well as practical research in entrepreneurial innovation.

He is currently holding a Research Fellow position at the Griffith Business School. Prior to his academic career, how worked for more than 10 years in the logistics industry for a Fortune 500 company in various professional and management positions.

ORCID ID: https://orcid.org/0000-0002-4023-2282 